\title{
MOTIVOS DA BAIXA PARTICIPAÇÃO DE HOMENS IDOSOS EM UM PROJETO DE ATIVIDADE FÍSICA
}

\section{REASONS FOR THE LOW PARTICIPATION OF OLDER MALE ADULTS IN A PROJECT OF PHYSICAL ACTIVITY}

\author{
Doralice Lange de Souza* \\ ORCID: https://orcid.org/0000-0001-7330-6156 \\ Rosecler Vendruscolo** \\ ORCID: https://orcid.org/0000-0002-0281-8645
}

\section{Resumo}

A pesquisa, de cunho qualitativo e exploratório, teve como objetivo mapear os motivos da baixa participação de homens em um projeto de extensão universitária denominado "Sem Fronteiras: atividades corporais para adultos maduros e idosos", desenvolvido na Universidade Federal do Paraná. Entrevistamos individualmente ou em grupos focais 16 homens que frequentavam o projeto, 4 ex-participantes e 3 que nunca haviam participado, mas conheciam o projeto através de suas esposas. Os principais motivos da baixa participação são: eles tendem a não se identificar com os interesses do público do projeto, preponderantemente feminino; não querem expor as limitações adquiridas com o processo de envelhecimento; buscam evitar compromissos com atividades de cunho obrigatório; não se sentem atraídos pela natureza e intensidade das atividades ofertadas. Este trabalho oferece subsídios para o planejamento de projetos de atividade física para idosos que almejem atrair o público masculino.

Palavras-chave: Idoso; Homem; Atividade física; Projeto; Participação.

\begin{abstract}
This is a qualitative and exploratory study that aimed to map the reasons for the low participation of men in a university extension project called "Without Borders: bodily activities for mature and elderly adults", developed at the Federal University of Paraná. We developed individual or focus group open interviews with 16 men who attended the project, four former participants and three men who had never participated in the project, but had heard of it through their wives. The main reasons for the low participation are: they tend not to identify themselves with the interests of the predominantly female participants; they do not want to expose the limitations related to their aging; they seek to avoid commitments to mandatory activities; they are not attracted by the nature and intensity of the activities offered. This work offers information to support the planning of physical activity projects that aim to attract the male audience.
\end{abstract}

Keywords: Older adult; Men; Physical activity; Project; Participation. 


\section{Introdução}

Há um crescente reconhecimento da importância da atividade física para a saúde, bemestar, socialização e lazer de idosos (OKUMA, 1998; VENDRUSCOLO, 2013). Mas a porcentagem de idosos inseridos em programas de atividade física supervisionados é ainda baixa (CARDOSO et al., 2008; DEBERT, 2013; MEDEIROS et al., 2014; MELLO; VOTRE, 2013), o que se aplica ainda mais ao universo masculino. Conforme apontam alguns estudos, a presença de mulheres nestes programas é maior do que o número de homens (ANDREOTTI; OKUMA, 2003; CARVALHO; MADRUGA, 2011; DEBERT, 2004; MARTINS; GONÇALVES, 2018; QUEIROZ, 2011), o que acontece não só no Brasil, mas também em outros países, como, por exemplo, nos Estados Unidos (ANDERSON et al., 2016).

São poucas as pesquisas que exploraram os fatores que influenciam a baixa participação de homens nestes programas (ANDERSON et al., 2016; MEDEIROS et al., 2014). Dentre os fatores apontados, destacam-se: falta de interesse (LIMA; BARBOSA, 2014); falta de identificação com as atividades (ANDERSON et al., 2016; COUTINHO; ACOSTA, 2009; MELLO; VOTRE, 2013; QUEIROZ, 2011) e/ou com a intensidade das atividades ofertadas (CARVALHO; MADRUGA, 2011); preferência por atividades não obrigatórias (MELLO; VOTRE, 2013); preferência por atividades que envolvem vínculos de amizades (COUTINHO; ACOSTA, 2009; QUEIROZ, 2011); falta de tempo (QUEIROZ, 2011); negação da velhice (QUEIROZ, 2011) ; vergonha das limitações desenvolvidas com o processo de envelhecimento (LIMA; BARBOSA, 2014; QUEIROZ, 2011) e temor de colocar a masculinidade à prova devido às fragilidades desenvolvidas com este processo (MEDEIROS et al., 2014; MELLO; VOTRE, 2013; QUEIROZ, 2011).

Considerando a baixa participação de homens em projetos sociais de atividades físicas e visando colaborar para com a literatura ainda escassa que busca explicar este fenômeno, desenvolvemos um estudo para explorar algumas hipóteses que possam explicar o pouco envolvimento de idosos do sexo masculino em um projeto de extensão universitária denominado "Sem Fronteiras: atividades corporais para adultos maduros e idosos" (PSF).

Escolhemos o PSF por ser coordenado por uma das autoras deste trabalho e por buscarmos alternativas para atrair mais homens para o projeto. Além disto, como o projeto existe já há 20 anos, a experiência dos homens participantes, ex-participantes e dos cônjuges das participantes mulheres que escolheram nunca participar do projeto, apesar das oportunidades de integração no mesmo ao longo dos anos, pode nos ajudar a explorar com mais profundidade o nosso objetivo de pesquisa.

Visamos com este trabalho gerar conhecimentos que possam contribuir para uma melhor adesão e aderência de homens idosos tanto no projeto pesquisado quanto em outros com características similares. 


\section{Método}

A pesquisa foi de cunho qualitativo e exploratório e aprovada pelo Comitê de Ética em Pesquisa da UFPR, parecer n. CEP/SD 697.032.09.05. Seguimos todos os procedimentos aprovados, inclusive a aplicação do Termo de Consentimento Livre e Esclarecido. Utilizamos pseudônimos para garantir o anonimato dos participantes.

O PSF acontece no Departamento de Educação Física da Universidade Federal do Paraná (UFPR), em Curitiba, desde o ano de 1999, e é ofertado para duas turmas distintas: manhã e tarde. Ele caracteriza-se por ser um programa de atividades físicas e socioculturais voltadas a adultos de meia-idade e idosos. Os objetivos principais do PSF são: (1) a formação teórica e prática de acadêmicos para a intervenção na área do envelhecimento, da velhice e da atividade física; (2) proporcionar uma melhor autonomia, qualidade de vida, atualização cultural e integração social para os participantes do projeto.

As atividades desenvolvidas no projeto são: alongamentos, caminhadas, ginásticas, musculação, danças, jogos recreativos e hidroginástica. A realização dessas atividades é dividida em duas etapas, uma voltada à socialização e a outra voltada ao condicionamento físico. No período em que coletamos os dados, participavam do projeto pessoas de 50 a 87 anos de idade, de diferentes níveis educacionais e socioculturais.

Quanto à escolaridade, $21 \%$ dos participantes do PSF tinham o ensino fundamental fase I; $10 \%$ o ensino fundamental fase II; $41 \%$ o ensino médio; $18 \%$ nível superior completo, e $10 \%$ pós-graduação (especialização). Com relação ao estado civil, $61 \%$ eram casados; $29 \%$ viúvos; 7\% divorciados, e 3\% solteiros. Quanto aos proventos, 4\% recebiam menos que 1 salário-mínimo (SM); $41 \%$ entre 1 e 2,9 SM; $20 \%$ entre 3 e 4,9 SM; $18 \%$ entre 5 e 6,9 SM; $10 \%$ entre 7 e 8,9 SM, e 7\% de 9 a 11 SM. Embora o projeto seja aberto para participantes de ambos os sexos, a grande maioria dos integrantes tem sido de mulheres desde a sua implementação.

Realizamos a coleta de dados através de grupos focais e entrevistas individuais realizadas nas instalações do próprio local do projeto. A primeira coleta foi realizada em 15 de setembro de 2015. Na época, havia ao todo 64 mulheres e 11 homens no PSF. Convidamos todos os 6 homens participantes do turno da tarde e todos compareceram. A segunda coleta ocorreu em 20 de setembro 2018. Na época, havia o total de 62 mulheres e 20 homens participando no projeto. Convidamos todos os 16 que participavam no turno da manhã e 10 compareceram. A terceira coleta foi realizada em 28 de março de 2019. Na época, havia-64 mulheres e 15 homens no projeto. Convidamos todos os cônjuges das mulheres para participarem da dinâmica e somente 3 compareceram: 2 ex-participantes e 1 que nunca participou do PSF. Repetimos o convite para os cônjuges das participantes duas outras vezes, em maio de 2019. No primeiro chamado, 2 ex-participantes compareceram. No segundo, vieram 2 homens que nunca haviam participado do projeto.

As entrevistas foram abertas e duraram aproximadamente uma hora cada. Estas tiveram como pergunta inicial: em sua opinião, por que existe pouca participação de homens no projeto? Com base nas respostas, levantamos outras perguntas para melhor entendermos 
o ponto de vista dos participantes. Gravamos e transcrevemos todas as entrevistas na íntegra, bem como atribuímos pseudônimos aos entrevistados para evitar a sua identificação.

Realizamos uma análise temática das entrevistas, seguindo o passo a passo sintetizado por Braun e Clarke (2006). As entrevistas foram, primeiramente, analisadas individualmente e, a seguir, contrastamos as respostas obtidas através das diferentes dinâmicas. Agrupamos os principais temas que emergiram dos dados em categorias, por meio das quais buscamos compreender os principais motivos para a baixa presença de participantes do sexo masculino no PSF. Como durante o processo de análise percebemos que os homens participantes do projeto tinham perspectivas um pouco diferentes dos ex-participantes e daqueles que nunca haviam participado do projeto, também organizamos os dados de forma a comparar as possíveis diferenças nas respostas destes grupos.

\section{Resultados e discussão}

Participaram 23 idosos entre 62 e 84 anos de idade, de diferentes níveis econômico, social e educacional. Os participantes citaram vários motivos para a baixa participação de homens no projeto. Em virtude dos limites deste trabalho, discorreremos apenas sobre os temas mais frequentes e que foram citados por, pelo menos, 4 participantes.

\section{Os homens tendem a não querer participar em grupos majoritariamente femininos}

A explicação mais citada para a baixa participação de homens no PSF - 22 dos 23 participantes - é que os homens não gostam de se envolver em grupos de atividade física onde a maioria dos participantes é do sexo feminino. Este fator foi também citado como importante em outro estudo desenvolvido nos Estados Unidos (ANDERSON et al., 2016). De acordo com os nossos entrevistados, os homens tendem a sentir vergonha de fazer atividade física com mulheres. Vejamos alguns exemplos de depoimentos neste sentido:

Tem homens que têm vergonha de fazer exercícios de academia junto com as mulheres $[\ldots]$ eu mesmo já chamei meu irmão para vir, mas ele não vem, tem vergonha de chegar e ficar no meio de mulheres. (Augusto, 70 anos, participante)

Não atrai muito porque sou mesmo expansivo de falar, mas tem coisa que eu tenho vergonha de fazer [...] Tá todo mundo junto ali! [...] E aqui tem aquela mulherada! (Claudio, 73 anos, nunca participou)

De acordo com os entrevistados, muitos homens tendem a não se sentir à vontade com as mulheres:

Eles ficavam intimidados por causa que a maioria naquela época era de mulheres $[\ldots]$, como hoje continua sendo. [...] Muitos não têm liberdade de conversar e 
dialogar com as mulheres né? [...] As mulheres, na verdade, elas conversam entre elas, né? E os homens entre os homens, né? (Arnaldo, 71 anos, participante)

Aparentemente, muitos homens não se identificam nem com os conteúdos, nem com o estilo das conversas das mulheres:

[Quando] elas estão reunidas sempre o bate-papo é com mais ênfase do que quando os homens estão reunidos, até porque os interesses são outros, a postura é outra, uma "papagaiada", como diz a turma, né? (Breno, 77 anos, participante)

Eles tendem a preferir conversar com outros homens. Um dos entrevistados chegou a comentar que, em um determinado período do projeto, quando não havia outros homens, ele só conversava com os professores.

Tinha dois professores [...]. Eu então conversava com eles. Eles eram os únicos homens do projeto. Não tinha mais com quem eu conversar! (Arnaldo, 71 anos, participante)

Vinte entrevistados disseram que as mulheres tendem a focar mais na socialização e conversas do que na atividade física. Isto os desmotivava/desmotiva a participar do projeto.

O ritmo das mulheres é diferente dos homens. O homem não vem aqui não é só porque não tem aparelho [equipamentos de musculação]! É porque tem muita conversação! A gente é focado nas coisas! [...]. Tem gente que vem aqui pela companhia! [...] Eu queria fazer mais! [...] Senhora, dê o lugar para outra pessoa! Elas vêm aqui para uma reunião social mesmo! (Samir, 74 anos, ex-participante)

Às vezes, eu me irritava. Tinha aqueles exercícios para fazer. E tem umas comadres lá que sentam e ficam conversando e ficavam lá sentadas ocupando o lugar. Eu não gostava disto! A esteira, quem pegava ficava às vezes o tempo todo! (Paulo, 76 anos, ex-participante)

Embora os dados não tenham revelado conflito de interesses entre os homens que frequentam o programa - este estudo não investigou esta questão - vale ressaltar que outra pesquisa demonstrou que alguns homens procuram programas de atividade física em grupo para socializar. Isto pode gerar uma tensão entre estes homens e aqueles que têm como foco principal a atividade física (DUNLOP; BEAUCHAMP, 2013).

\section{O problema dos "ismos": capacitismo, machismo e idadismo}

Outra razão levantada pelos entrevistados foi que os homens não querem expor as suas fragilidades, especialmente se o grupo for essencialmente feminino:

A pessoa que tá fora, que está em casa, ela não põe a cara para bater no meio de 50 mulheres. Eles não vêm não se entregam assim! É questão de princípio! Você 
chegar com a cara limpa no meio de 50 mulheres? [...]. Então é difícil. (Toffoli, 84 anos, participante)

Seis entrevistados disseram que os homens temem ser julgados como menos capazes do que eram anteriormente percebidos. Este medo está conectado com o que alguns autores chamam de "ableism" ou "capacitismo". Na perspectiva ableist ou capacitista, o valor da pessoa é medido pelo quanto ela é capaz de realizar determinadas tarefas. Como os idosos tendem a tornar-se mais limitados para desempenhar algumas funções em consequência de seu envelhecimento, muitos temem ser percebidos como incapazes, improdutivos, dependentes e/ou dignos de pena (COAKLEY, 2017).

De acordo com os mesmos 6 entrevistados citados, muitos homens receiam, inclusive, que a sua masculinidade seja colocada à prova.

[...] Acho que isto tem a ver com o tal do nosso pensamento machista. O homem sempre se considerou mais forte, e neste sentido, não quer se entregar, não quer se mostrar fragilizado [...]. Não são todos os homens que vão ao médico quando precisariam [...]. Os homens têm este certo receio de participar, de ir ao médico, de participar de grupo, de fazer exercício e tal e coisa. (Breno, 77 anos, participante)

O homem se acha e tal, se sente mais superior e então se envergonha mais fácil! (Nilberto, 66 anos, participante)

A identidade masculina, normalmente associada à produção no mundo do trabalho e ao provento da família, tende a ser afetada com o processo de envelhecimento e aposentadoria (QUEIROZ, 2011). Os homens não querem ser percebidos e se identificar com uma condição de fragilidade e vulnerabilidade, uma vez que esta nova imagem de si pode contrapor-se aos seus atributos masculinos (ex. virilidade e força física), tais como eles eram anteriormente percebidos (ANDERSON et al., 2016; DEBERT, 2004; QUEIROZ, 2011).

Não é fácil para grande parte dos homens lidar com a sua gradativa perda de habilidade e força física. A situação pode ficar ainda mais difícil quando eles se depararam - e compararam - com as habilidades de colegas da mesma idade do sexo feminino (DUNLOP; BEAUCHAMP, 2013; SMITH et al., 2007). Como afirmam Dunlop e Beauchamp (2013, p. 224, tradução nossa), "quando um homem idoso percebe sua capacidade física como parte de sua identidade, poucos eventos lhes parecem mais ameaçadores para sua masculinidade do que a crença de paridade ou inferioridade entre o seu funcionamento físico e o de mulheres ao seu redor". Nestes casos, a participação em grupos de atividade física com pessoas do sexo oposto pode ameaçar o seu senso de identidade.

Os homens temem comprometer a sua imagem de provedores, protetores e chefes de família (LIMA; BARBOSA, 2014; MELLO; VOTRE, 2013; QUEIROZ, 2011). Conforme apontam alguns autores, o preconceito ou a vergonha que os idosos têm de evidenciar a sua fragilidade física, psíquica e social decorrentes do envelhecimento pode afastá-los de grupos orientados de atividade física e/ou a se retrair ao ambiente familiar (LIMA; BARBOSA, 2014; QUEIROZ, 2011). 
De acordo com 19 entrevistados, os homens também temem ser identificados como idosos.

\footnotetext{
Eu acho também que tem muitas pessoas que dizem que isto é coisa para velho [...]. E o homem tem este preconceito, assim como vamos dizer, ele acha que nunca vai ficar velho e este tipo de coisa! [...] Acha que vai ser sempre jovem. (Nilberto, 66 anos, participante)
}

Houve uma confraternização entre amigos e perguntaram o que eu estava fazendo, enfim, eu falei do projeto da terceira idade. Eles disseram: sai daí! Que é isso? Ficar no meio da velharada? [...] Vai ficar com os jovens para se sentir mais novo! (Patrício, 72 anos, participante)

O entrevistado Patrício nos contou, durante uma conversa informal, que no passado havia saído do PSF para participar em outro projeto focado na dança de salão, pois queria confraternizar com pessoas mais jovens. No entanto, os participantes do outro projeto não queriam dançar com ele porque o percebiam como velho. Da mesma forma que ele se afastou de seus pares do PSF porque eram idosos, os seus novos colegas se afastaram dele devido à sua idade. Ele, como muitos de nós, somos algozes e vítimas do que alguns autores chamam de "ageism" ou "idadismo". Conforme explica Coakley (2017), o idadismo é uma perspectiva que avalia e discrimina as pessoas de acordo com sua idade. Nela, acredita-se que quanto mais idosas as pessoas são, mais elas são frágeis, limitadas e incapazes. Este tipo de preconceito leva muitas pessoas a sentirem medo do envelhecimento. A ironia desta perspectiva é que, na medida em que envelhecemos, todos acabaremos sofrendo os mesmos preconceitos que incorporamos e reproduzimos quando ainda mais jovens em relação às pessoas idosas.

\section{Preguiça e acomodação e/ou preferência por atividades mais vigorosas}

Quinze entrevistados que participam do PSF alegaram que um importante fator para a baixa participação dos homens no projeto é a preguiça e a acomodação.

Mas é preguiça mesmo! Os homens em geral são preguiçosos, em tudo né? Preferem ficar em casa assistindo televisão! (Tadeu, 67 anos, participante)

O homem tem mais preguiça. Acomodação também. Por que o homem não vai para o médico? Mais por comodismo. Acho que neste ponto as mulheres são mais conscientes das coisas. (Patrício, 62 anos, participante)

Muitos homens não gostam de exercício, falta esforço, falta vontade para chegar lá. (Augusto, 70 anos, participante)

Quatro participantes alegaram que os homens tendem a não acreditar na importância da atividade física para a saúde: 

Homens são preguiçosos e não acreditam que o exercício é bom. (Miguel, 69 anos,
participante)

Eu acredito que os homens não acreditam no exercício, em por que fazer exercício! (Junior, 71 anos, participante).

Um estudo realizado em três espaços de lazer frequentados por idosos concluiu que, embora os homens tendam a considerar a atividade física orientada necessária, muitos acreditam que não precisam fazer exercícios físicos enquanto tiverem um bom desempenho físico para realizar determinadas tarefas (COUTINHO; ACOSTA, 2009). Como o processo de envelhecimento é lento e nem sempre visível no curto prazo, eles tendem a não perceber determinadas mudanças em seu corpo e, consequentemente, não se engajam em atividade física. As construções culturais de masculinidade, principalmente em relação à crença na imunidade, afetam o autocuidado em saúde e a participação de homens em projetos sistematizados de atividade física (MEDEIROS et al., 2014).

No caso do presente estudo, 4 dos 7 entrevistados que não participam do projeto apresentaram argumentos que contradizem o que foi dito anteriormente, quanto à suposta preguiça dos homens para se engajar em atividade física e a sua suposta negação da necessidade da atividade física para a saúde. Estes 4 entrevistados alegaram que não participam do projeto justamente porque acham as atividades propostas muito fracas e por preferirem se engajar em atividades mais vigorosas:

Era muito devagar! Não era objetivo aqui! Era uma encheção de linguiça para gastar o tempo com a gente! (Paulo, 76 anos, ex-participante)

Eu não venho aqui porque segunda, quarta, quinta e sexta eu corro $6 \mathrm{~km}$ por dia [...]. E aí é por isto que eu não venho aqui [...]. Para quem não faz nada é ótimo! [...]. Aqui é um divertimento e é legal. Mas para mim não dá! (Sérgio 2, 74 anos, nunca participou)

Quatro entrevistados que nunca participaram e/ou desistiram do projeto disseram que prefeririam que as atividades propostas fossem mais objetivas, mais "diretas ao ponto", ou seja, diretamente focadas na prática de atividade física:

\footnotetext{
Mas eu sou muito objetivo. Eu venho aqui para fazer alongamento, ginástica [...]. Então tinha enchimento com brincadeiras. Eu venho aqui para fazer isto, eu vou fazer isto! Tinha muito enchimento de tempo com festinha. [...]. Os professores às vezes ficavam enchendo o tempo. Então eu optei por ir para uma academia perto de casa. Lá eu vou cinco vezes por semana. (Samir, 74 anos, ex-participante)
}

Contrariamente à afirmação de que os homens tendem a não admitir a importância da AF para a sua saúde, alguns entrevistados disseram que não participam do projeto justamente porque estão preocupados com isto. 
Eu vou fazendo até quando Deus permitir! [...]. Eu perdi muita massa muscular. Então, eu tenho que ser muito objetivo. Não dá para perder tempo com festinha, coisinha, conversinha. Não dá! Eu trago a minha mulher aqui e vou na academia! (Samir, 74 anos, ex-participante)

No caso dos entrevistados que nunca participaram ou que são ex-participantes do PSF, todos fazem algum tipo de atividade física ou esportiva regularmente. Ou seja, os homens não são mais preguiçosos que as mulheres para a prática da atividade física. Eles participam menos de programas orientados e em grupo de atividade física porque tendem a preferir outros tipos de atividades, normalmente mais vigorosas e/ou competitivas (ANDERSON et al., 2016).

De acordo com o Instituto Brasileiro de Geografia e Estatística (IBGE, 2017), com base em dados coletados em 2015, das 161,8 milhões de pessoas com 15 anos ou mais no Brasil, 61,3 milhões (37,9\%) praticavam algum tipo de atividade física ou esportiva. Se consideradas as devidas proporções de homens $(47,8 \%)$ e mulheres $(52,2 \%)$, os níveis de atividade física deles são de $42,7 \%$ e $33,4 \%$, respectivamente. Do total de praticantes de atividade física, 15,7 milhões eram mulheres e 12,5 milhões homens. Já do total de praticantes de esporte, 24,5 das pessoas eram do sexo masculino e 14,3 do sexo feminino.

O Diagnóstico Nacional do Esporte - DIESPORTE (BRASIL, 2016) concluiu que, dentre os brasileiros que possuem entre 55 e 64 anos, os esportes mais praticados são o futebol $(38,40 \%)$, caminhada $(36,10 \%)$ e natação $(3,30 \%)$. Já dentre a população que possui de 65 a 74 anos, as atividades preferidas são a caminhada (37,7\%), futebol $(26,20 \%)$ e ginástica (23,9\%). Embora o DIESPORTE não tenha divulgado dados que nos permitam identificar as diferenças de gênero nas escolhas destas atividades, pode-se inferir que existe um número significativamente maior de homens do que de mulheres envolvidos com o futebol nesta faixa etária, uma vez que este é ainda um esporte preponderantemente masculino no Brasil.

Tanto os questionários utilizados para a coleta de dados do IBGE quanto para o DIESPORTE não diferenciaram AF de esporte, o que não nos permite inferir o número real de pessoas envolvidas com o esporte ou com a atividade física. Os dados disponibilizados por ambos os estudos também não nos permitem inferir quais as preferências da população, em termos de atividade física ou esportiva, considerando a faixa etária e gênero concomitantemente. Apesar destas limitações, no entanto, podemos deduzir que os homens brasileiros se envolvem mais em atividades esportivas do que em atividades físicas. Já as mulheres preferem atividades físicas. Isto nos leva à hipótese de que, talvez, para alguns homens, o projeto não seja muito atrativo porque ele não prioriza a prática esportiva. Esta hipótese se fortalece diante de alguns comentários que foram feitos durante a entrevista, como, por exemplo:

Tem homens que gostam do esporte. Eu gostava do futebol, eu era fanático por futebol e sempre treinando e jogando [....]. E então assim, para quem joga bola, por exemplo, não vai se interessar [pelo projeto], né? (Patrício, 62 anos, participante) 
Quando perguntamos aos participantes o que poderia ser feito para que o projeto tivesse mais homens, uma das principais sugestões foi a de que ele poderia ofertar mais atividades esportivas.

Atividades mais esportivas talvez [...] eu acho que atrai mais os homens [...]. Mas ali do jeito que tá você não vai poder incluir essas coisas mais para homens, porque senão a mulherada não vai gostar. Então, tem que agradar a maioria, e as atividades têm que ser uma média. (João, 77 anos, participantes)

Se o número de homens e mulheres no projeto fosse mais equilibrado, talvez a sugestão acima fosse mais viável. Alguns entrevistados sugeriram que, para um maior equilíbrio, os homens deveriam ser colocados na frente das mulheres na fila de espera para entrar projeto antes delas até que haja uma equivalência no número de homens e mulheres.

\section{Vida profissional e envolvimento com outros tipos de atividade}

Um motivo que foi levantado por 7 entrevistados que participam do projeto é que, talvez, alguns homens não participem porque trabalham ou estão envolvidos com tarefas familiares, como ajudar filhos e netos. Ainda, outra hipótese citada é que muitos homens não participam por não quererem compromissos fixos e estruturados:

\footnotetext{
Eu acho que um dos fatores pode ser que a pessoa, antes de conhecer o projeto, acha que vai ser muito rígido. É com professores! [...] E quando a pessoa vem e conhece, vê que é bem descontraído [...]. Se você não puder fazer, os próprios professores orientam: "não faça!" [...]. Ele [o homem] quer coisas mais descontraídas! (Alcir, 71 anos, participante)
}

Os homens tendem a preferir atividades que lhes proporcionem companhia, sociabilidade e prazer de forma não obrigatória e com a possibilidade de exercer a sua autonomia (COUTINHO; ACOSTA, 2009; MELLO; VOTRE, 2013). Coutinho e Acosta (2009), por exemplo, verificaram que os homens idosos participantes de seu estudo preferiam atividades como a bocha, cartas e jogo de sinuca a atividades físicas supervisionadas, por considerá-las pouco estimulantes e repetitivas. Eles também preferiam ir a lugares frequentados por longa data com os amigos para conversa, visando descontração, divertimento e integração. Com a aposentadoria e mais tempo livre, eles queriam aproveitar mais esses ambientes e atividades de forma mais espontânea.

Vale ressaltar, conforme apontam vários autores (ANDREOTTI; OKUMA, 2003; COUTINHO; ACOSTA, 2009; VENDRUSCOLO; LOVISOLO, 1997), que os homens acima de 60 anos contam com mais pontos de encontros socialmente aceitáveis, como bares, cafés, grêmios recreativos, clubes, entre outros, do que as mulheres. Este argumento pode ajudar a explicar a pouca participação de homens em projetos tais como o PSF. Alguns depoimentos de ex-participantes e pessoas que nunca participaram do PSF disseram que não 
dependem de ambientes tais como o do PSF para socializar. Desta forma, quando se engajam em alguma prática de atividade física, preferem fazer isto de forma mais objetiva.

Elas preferem vir mais aqui por causa da atividade social. O homem não faz tanta questão de atividade social. A gente tem a nossa atividade! (Sérgio 2, 74 anos, nunca participou)

As experiências de mulheres em programas de atividade física lhes proporcionam momentos de convívio e afirmação pessoal fora do âmbito do lar, principalmente quando elas não encontram outras oportunidades de socialização e atuação (VENDRUSCOLO; LOVISOLO, 1997). Essas vivências em programas de atividade física também significam liberdade de funções tradicionalmente atribuídas a elas em suas casas, propiciando-lhes momentos de autocuidado, satisfação individual e ampliação de seu repertório de ação (VENDRUSCOLO; GODOY, 2011).

Para finalizar, faz-se interessante citar, ainda, dois estudos que tratam da temática. O primeiro envolveu 989 pessoas de ambos os sexos, com idade entre 50 e 79 anos, e também constatou diferenças de gênero em relação à preferência pelos locais para a prática de atividades físicas. Os pesquisadores concluíram que as mulheres se envolviam mais em atividades em locais com supervisão (88,7\%), se sentiam mais seguras em espaços fechados do que em espaços abertos e preferiam receber atenção e afetividade de um profissional da Educação Física. Já a maioria dos homens praticava atividade física nos locais sem supervisão profissional. Contudo, a presença de homens $(49,7 \%)$ e mulheres $(50,3 \%)$ nesses lugares era equilibrada. Os autores verificaram que os homens eram mais suficientemente ativos $(67,9 \%)$ do que as mulheres (48\%). Vale ressaltar que, para fins deste estudo, foram consideradas suficientemente ativas as pessoas que praticam, pelo menos, 150 minutos por semana de caminhada e/ou atividade física moderada ou vigorosa (CARVALHO; MADRUGA, 2011).

O segundo estudo investigou os benefícios percebidos por 119 idosos no uso dos pontos de encontros comunitários do Distrito Federal nos processos de socialização, estados de humor e qualidade de vida. Os autores identificaram uma maior participação de homens $(51,3 \%)$ do que mulheres $(48,7 \%)$ nesses espaços. Embora a diferença na participação de ambos os sexos não seja significativa, esta pesquisa indica uma preferência de homens idosos por tais espaços e pelas atividades físicas ali propiciadas (AZEVEDO FILHO et al., 2019).

\section{Conclusão}

Diversas foram as explicações para a baixa participação de homens no PSF. A principal, citada por quase todos os entrevistados, é que eles não se sentem atraídos pelo projeto porque tem um público majoritariamente feminino. Vários também disseram que os homens tendem a sentir vergonha de estar em grupos com este tipo de público e/ou não se identificam com a "conversarada da mulherada". 
Outro fator citado foi que eles não querem expor as suas fragilidades e limitações adquiridas ao longo de seu processo de envelhecimento. Isto, de acordo com alguns participantes do projeto, supostamente poderia colocar a sua masculinidade à prova. Ainda outro fator mencionado é que muitos homens não participam de grupos de idosos porque não querem ser percebidos como velhos e desejam evitar estigmas negativos normalmente associados à velhice. Todos estes fatores são consistentes com o que a literatura sobre o assunto vem indicando.

A maioria dos idosos que participam do projeto também disse que os homens tendem a ser preguiçosos e acomodados, o que dificulta a sua participação no projeto. Esta explicação, no entanto, foi contestada por depoimentos de ex-participantes e de homens que nunca participaram do projeto e que buscaram outras práticas de atividade física justamente porque queriam se envolver em práticas de atividade física de forma mais objetiva e vigorosa.

Houve entrevistados que levantaram a hipótese de que os homens não participam do projeto porque evitam compromissos e atividades muito estruturadas. Depois de uma vida ativa no mundo do trabalho, ao aposentar-se, preferem não ter obrigações que comprometam o livre uso de seu tempo e energia. Alguns também disseram que, como eles tendem a ter uma vida social mais ativa do que muitas mulheres, eles não têm necessidade de procurar grupos de atividade física para suprir a sua necessidade de se socializar. Sendo assim, optam por atividades físicas mais focadas na prática em si.

Alguns fatores citados no decorrer deste trabalho, dentre outros que possivelmente existam, causam uma espécie de ciclo vicioso que faz com que poucos homens participem no PSF e, possivelmente, em outros projetos afins. A preponderância de mulheres no projeto afugenta o engajamento de homens no mesmo. Em permanecendo com poucos homens, esses projetos não conseguem atrair mais indivíduos do sexo masculino.

Embora este trabalho tenha sido limitado no sentido de ter abordado apenas participantes, ex-participantes e não participantes de um projeto específico, ele ajuda a confirmar alguns achados de outras pesquisas. Mais estudos que envolvam investigações na área são necessários para que se possa continuar aprofundando as discussões, de forma a subsidiar o planejamento e desenvolvimento de projetos mais atrativos para o público masculino.

\section{Referências}

ANDERSON, C. et al. Recruiting and Engaging Older Men in Evidence-Based Health Promotion Programs: Perspectives on Barriers and Strategies. Journal of Aging Research, v. 2016, p. 1-8, 2016.

ANDREOTTI, M. C.; OKUMA, S. S. Andreotti MC, Okuma SS. Perfil sócio-demográfico e de adesão inicial de idosos ingressantes em um programa de Educação Física. Revista Paulista de Educação Física, v. 17, n. 2, 2003. 
AZEVEDO FILHO, E. R. DE et al. The perception of the elderly about the benefits of practicing physical activity: a study at the Community Meeting Points of the Distrito Federal. Revista Brasileira de Ciencias do Esporte, v. 41, n. 2, p. 142-149, 2019.

BRASIL. Ministério do Esporte. Diesporte. Caderno 2. O Perfil do Sujeito Praticante ou não de Esportes e Atividades Físicas da População Brasileira. Brasília: Ministério do Esporte, 2016.

BRAUN, V.; CLARKE, V. Using thematic analysis in psychology. Qualitative Research in Psychology, v. 3, n. 2, p. 77-101, 2006.

CARDOSO, A. S. et al. Fatores Influentes na Desistência de Idosos em um Programa de Exercício Físico. Movimento (ESEF/UFRGS), v. 14, n. 1, p. 225-239, 2008.

CARVALHO, R. B. da C.; MADRUGA, V. A. Envelhecimento e prática de atividade física: a influência do gênero. Motriz, v. 17, n. 2, p. 328-337, 2011.

COAKLEY, J. Sports and society: issues and controversies. New York: McGraw-Hill Education, 2017.

COUTINHO, R. X.; ACOSTA, M. A. DE F. Ambientes masculinos da terceira idade. Ciência \& Saúde Coletiva, v. 14, n. 4, p. 1111-1118, 2009.

DEBERT, G. G. A reinvenção da velhice: socialização e processos de reprivatização do envelhecimento. Campinas: EDUSP, 2004.

DEBERT, G. G. Feminismo e velhice. Sinais Sociais, v. 8, n. 22, p. 15-38, 2013.

DUNLOP, W. L.; BEAUCHAMP, M. R. Birds of a feather stay active together: A case study of an all-male older adult exercise program. Journal of Aging and Physical Activity, v. 21, n. 2, p. 222-232, 2013.

INSTITUTO BRASILEIRO DE GEOGRAFIA E ESTATÍSTICA - IBGE. Práticas de Esporte e Atividade Física. Pesquisa Nacional por Amostra de Domicílios. 2015. Rio de Janeiro: IBGE, 2017.

LIMA, F. L. N. DE; BARBOSA, R. M. dos S. Relatos sobre a participação masculina no programa Idoso Feliz Participa Sempre. Boletim Informativo Unimotrisaúde em Sociogerontologia, v. 5, n. 2, p. 82-98, 2014.

MARTINS, V. F.; GONÇALVES, A. K. O trabalho com o idoso: organização didáticopedagógica dos projetos de extensão universitária do curso de Educação Física. Revista Kairós: Gerontologia, v. 21, n. 1, p. 293-315, 2018. 
MEDEIROS, P. A. et al. Participação masculina em modalidades de atividades físicas de um programa para idosos: Um estudo longitudinal. Ciência e Saúde Coletiva, v. 19, n. 8, p. 3479-3488, 2014.

MELLO, J. G.; VOTRE, S. J. Fatores que interferem na participação de homens idosos em programas de esporte e laze. Pensar a Prática, v. 16, n. 4, p. 956-1270, 2013.

OKUMA, S. S. O idoso e a atividade física. Campinas: Papirus, 1998.

QUEIROZ, S. B. de. Educação e envelhecimento: um olhar sobre a participação masculina nos grupos de terceira idade de Manaus. 2011. Dissertação (Mestrado em Educação) Universidade Federal do Amazonas. Manaus, 2011.

SMITH, J. A. et al. I've been independent for so damn long!: Independence, masculinity and aging in a help seeking context. Journal of Aging Studies, v. 21, n. 4, p. 325-335, 2007.

VENDRUSCOLO, R. Análise da produção do conhecimento sobre envelhecimento, velhice e atividade física em teses e dissertações (1987-2011). 2013. Tese (Doutorado em Educação Física - Universidade Federal do Paraná, Curitiba, 2013.

VENDRUSCOLO, R.; GODOY, L. Um estudo sobre a participação de mulheres em programas de atividade física para idosos. In: SEMINÁRIO NACIONAL DE SOCIOLOGIA E POLÍTICA, 3., 2011, Curitiba. Anais... Curitiba: 2011.

VENDRUSCOLO, R.; LOVISOLO, H. Representações de pessoas idosas sobre as atividades corporais. Motus Corporis: Revista de Divulgação Científica do Mestrado e Doutorado em Educação Física, v. 4, n. 2, p. 14-48, 1997. 